\title{
Feasibility of a Brief Online Mindfulness and Compassion-Based Intervention to Promote Mental Health Among University Students During the COVID-19 Pandemic
}

\author{
Marian González-García ${ }^{1}$ (D) - Jorge Crespo Álvarez ${ }^{1}$ - Elena Zubeldia Pérez ${ }^{1} \cdot$ Samuel Fernandez-Carriba $^{2}$. \\ Javier González López ${ }^{1}$
}

Accepted: 10 April 2021 / Published online: 17 May 2021

(C) The Author(s), under exclusive licence to Springer Science+Business Media, LLC, part of Springer Nature 2021

\begin{abstract}
Objectives The COVID-19 pandemic constitutes a global mental health challenge that has disrupted the lives of millions of people, with a considerable effect on university students. The aim of this study was to assess the feasibility of a brief online Mindfulness and Compassion-based Intervention to promote mental health among first year university students during COVID19 home confinement.

Methods Participants ( $n=66$ ) were first-year psychology students from a university in Spain with no prior meditation experience. Intervention lasted for 16 days and was designed ad-hoc. Using a pre-post within-subjects design, feasibility was assessed in five domains (acceptability, satisfaction, implementation, practicality, and limited efficacy testing). Participants completed both baseline and post-intervention assessments of perceived stress, anxiety, and self-compassion.

Results The intervention showed to be feasible in all domains evaluated. It was implemented as planned with constrained resources, and limited efficacy testing showed promising results. After the intervention, stress and anxiety levels decreased significantly ( $p<0.001$, Hedges's $\mathrm{g}=0.5146 ; p<0.001$, Hedges's $\mathrm{g}=0.6068$, respectively) whereas self-compassion levels were augmented significantly $(p<0.001$, Hedges's $g=0.6968)$.

Conclusions Our findings suggest that a brief online mindfulness and compassion intervention may be a feasible way of promoting mental health among university students during COVID-19 lockdown. Further studies are required to address the limitations of the present study. We conclude that online interventions may constitute a promising pathway to buffer the mental health burden derived from the COVID-19 pandemic.
\end{abstract}

Keywords Mindfulness $\cdot$ Compassion $\cdot$ Online $\cdot$ COVID-19 $\cdot$ University students $\cdot$ Mental health

The cascade of events that led to the outbreak of the coronavirus pandemic in 2019 (COVID-19) brought to light the reality of the interdependence that binds all sentient beings. The transmission of a novel coronavirus, named Severe Acute Respiratory Syndrome Coronavirus 2 (SARS-CoV-2), from bats to humans (Platto et al., 2021), followed by the rapid human-to-human virus spread, resulted in a global health

Marian González-García

marian.gonzalez@uneatlantico.es

1 Faculty of Health Sciences, Universidad Europea del Atlántico (UEA), Calle Isabel Torres, 21, 39011 Santander, Cantabria, Spain

2 Department of Pediatrics, Emory University School of Medicine, Atlanta, USA challenge that is still threatening life across the planet. To date, the coronavirus epidemic continues to be a global health issue. Besides, the situation of alarm generated by COVID-19 has turned into a mental health challenge with unprecedented consequences. Both the outbreak itself and the ensuing preventative measures have had a deep impact on the mental health of thousands of millions of people all over the world (Luykx et al., 2020; Otu et al., 2020; Shigemura et al., 2020; Wang et al., 2020).

Motivated by its rapid spread, on March 11th, 2020, the World Health Organization (WHO) declared the coronavirus epidemic a pandemic (WHO, 2020). In order to prevent the propagation of the virus, most countries adopted measures such as social distancing, lockdown, and stay-at-home orders. This is the case in Spain, one of the most affected countries during the first months of the pandemic. During the first 2 
months, a strict lockdown was imposed, leaving most people confined in their homes. All nonessential activities were prohibited, and people were only allowed outside to buy food or go to the hospital. This strict confinement, together with the threat derived from the rising number of infections, led to great psychological suffering and significant adverse consequences for mental health (Brooks et al., 2020; GonzálezSanguino et al., 2020), especially in vulnerable groups such as university students (Araújo et al., 2020; Kaparounaki et al., 2020; Odriozola-González et al., 2020). During the beginning of the mandatory confinement, concerns emerged relative to the adverse psychological consequences of this unprecedented situation, especially since mental health problems have already been on the rise among university students in recent years (Auerbach et al., 2016; Bruffaerts et al., 2018; Storrie et al., 2010).

The first year of university represents a life transition that might constitute a crucial period for students' mental health (Cooke et al., 2006; Tosevski et al., 2010). During this time, they must cope with multiple challenges that can lead them to experience psychological stress and mental health problems, such as increasing responsibility, financial demands, pressure to succeed, and changes in their support network (Liu et al., 2019; Ross et al., 1999). In addition to the psychosocial stressors related above, the situation produced by the COVID-19 pandemic represents one more challenge to be faced. The burden of being physically confined, great uncertainty about the future academic situation, the adaptation to online classes during the first year of university while not knowing if and when exams would take place, social isolation, the limitation of not being able to perform other activities which usually help manage emotions (like going out with friends or participating in sports), the difficulties of cohabiting with family during confinement and the frustration triggered by the inability to focus on studies in spite of the newly available time, are among the factors leading to great psychological distress. All these challenges have contributed to a global mental health challenge in times of coronavirus. Indeed, they can account for the emergence of mental health issues in those without a history of mental disorders and make preexisting conditions worsen significantly (Luykx et al., 2020; Otu et al., 2020). Indeed, psychological stress can trigger mental health problems in the form of depression and anxiety. The first as a consequence of the effort of continued coping and the second as an anticipatory emotion (Horowitz et al., 1980). Furthermore, stress may have a deleterious effect on the immune system (Cohen et al., 2007), such as increased susceptibility to viral upper respiratory infections (Pedersen et al., 2010), which is a particular concern as regards COVID-19. Hence, various studies have drawn attention to the need to implement specific interventions with these vulnerable populations, as a way of preventing detrimental effects on their mental health (Kaparounaki et al., 2020; Luykx et al., 2020).
All in all, as the transition to university represents a crucial period for students' mental health, training students to effectively manage stress and regulate emotions during this time could be of great value.

Contemplative practices are core features of many religious and spiritual traditions that have been used for thousands of years to promote mental balance and genuine well-being (Wallace, 2005). Among them, mindfulness-based interventions (MBIs) constitute a promising approach to promote mental health in university students. Neuroscience research about mechanisms through which mindfulness produces its effects has pointed to attention, awareness, and selfregulation as common MBIs mechanisms of action (Tang et al., 2015; Vago \& Silbersweig, 2012). Mindfulness constitutes a mental training in which individuals learn to train their attention in order to gain a greater awareness of one's thoughts, emotions, bodily sensations, and behaviors. This enhanced awareness may strengthen the self-regulation skills needed to effectively cope with life challenges and develop a deeper sense of well-being (González-García et al., 2016). These mechanisms are of particular interest in the face of the COVID-19 pandemic. Teaching people to be more aware and to self-regulate could contribute not only to their own health, but to global health, as it may lead to more socially responsible behavior. As the COVID-19 pandemic has highlighted, the health of others and of the planet are interdependent with respect to our own actions from one moment to another.

There is compelling evidence on the effectiveness of MBIs in reducing stress and promoting mental health both in the general population and in a wide range of clinical populations (Chiesa \& Serretti, 2011; Goldberg et al., 2021; Khoury et al., 2015). Several review studies have shown that MBIs can promote mental health and psychological well-being in undergraduate students (Chiodelli et al., 2020; Halladay et al., 2019; McConville et al., 2017). Furthermore, MBIs have also been shown effective for reducing the stress of the college transition and fostering the adjustment of first-year university students (Ramler et al., 2016). Nevertheless, considering the restrictions imposed by mandatory home confinement, the only possible way to carry out such an intervention was online. A metanalysis of randomized controlled trials has found some evidence confirming the effectiveness of online MBIs to promote mental health, reducing stress, anxiety, and depression (Spijkerman et al., 2016). Moreover, one recent study utilizing a MBI during COVID-19 has found promising evidence of this kind of training to effectively promote mental health during the COVID-19 outbreak (Matiz et al., 2020). In relation to online MBIs in university students, some previous studies have found that this kind of training could reduce perceived stress (Cavanagh \& Millings, 2013), as well as anxiety and depression (El Morr et al., 2020).

MBIs can be classified into two generations of programs (Van Gordon et al., 2015). The first of these is represented by 
the first standardized mindfulness programs, Mindfulnessbased Stress Reduction (MBSR; Kabat-Zinn, 1990) and Mindfulness-based Cognitive Therapy (MBCT; Segal et al., 2002). The second generation of MBIs, which have emerged in recent years, encompasses a group of intervention programs characterized by the explicit training of self-compassion and compassion for others, defined as the desire for self and others to be free from suffering. Research has shown that this second generation of MBIs may promote mental health, social connection, and prosocial behavior (Kirby et al., 2017; Shonin et al., 2015, 2017). Interestingly, some studies have shown self-compassion may promote mental health by reducing psychological stress (Luo et al., 2019) and facilitating adaptive emotion regulation (Inwood \& Ferrari, 2018). Even more, a recent study found that self-compassion meditation practice was associated with better cohabitation during the Spanish lockdown (Jiménez et al., 2020). Besides, compassion cultivation has been proved to buffer against the deleterious effects of psychosocial stressors by reducing the reactivity of the autonomic stress response (Arch et al., 2014; Breines et al., 2014), and may be of particular interest during the current COVID-19 pandemic (Khoury, 2020).

In summary, the potential impact of the COVID-19 outbreak on the mental health of Spanish university students led us to design the current feasibility study. The purpose was to investigate the feasibility of an online MBI (E-Mindfulness) developed ad-hoc during the COVID-19 lockdown to promote first-year university students' mental health. Our hypotheses were (1) that implementing an online MBI during COVID-19 lockdown would be feasible, and (2) that students following the MBI would experience a decrease in their stress and anxiety levels, and an increase in self-compassion. The evaluation of feasibility was based on five of the criteria suggested by Bowen et al. (2009): acceptability, satisfaction, ease of implementation, practicality, and limited efficacy testing.

\section{Method}

\section{Participants}

Eighty-seven (87) first-year psychology students at a local university were invited to participate through university communication channels. An announcement on the university website asked for volunteers to participate in a mindfulness research study to learn to regulate their emotions and promote their well-being during the lockdown. Participation was strictly voluntary and no compensation or credits were offered for taking part in the study. Seventy-six (76) baseline responses and 70 post-intervention responses were received. At the beginning of the baseline tests, participants were asked to create a unique 8-character alphanumeric code using the following guideline: The alphanumeric code must include the first three letters of the mother's second surname, the first three letters of the father's second surname and the participant's date of birth. At the beginning of the post-intervention tests this alphanumeric code was asked again. A total of 66 responses were matched and were considered valid. The other four responses were dropped due to code mismatch.

Those 66 valid participants were of typical age for firstyear university students (mean age 19.83, SD 1.49, range $18-25$ with two missing values), and the majority were women $(86.36 \%)$. All participants were Caucasian except for two that were Latino. In total, $98.68 \%$ of the participants had no prior experience in mindfulness meditation.

\section{Procedures}

All procedures and measures for the intervention were approved by the University's Ethics Committee. The students who agreed to participate $(N=76)$ signed an informed consent form that specified the study's objectives and guaranteed the anonymity and confidentiality of the data. All assessments were done through an electronic survey platform. The baseline survey consisted of questions about demographic characteristics, previous mindfulness experience, and questionnaires for measuring stress, anxiety, and self-compassion. The postintervention survey was identical to the baseline one with the addition of questions on the feasibility of the intervention (see below in "Measures" for detailed information).

\section{Mindfulness Intervention}

The E-Mindfulness intervention was designed $a d-h o c$ in order to provide first-year university students with strategies to manage stress and regulate emotions during COVID-19 lockdown. The intervention was intended to promote mental well-being by enhancing attention, awareness, and selfregulation skills. Students learned to (1) focus their attention and stabilize their mind, (2) manage stress and develop healthy coping skills for challenging times, (3) regulate their emotions and develop self-compassion, (4) develop compassion for others, and (5) enhance their ethical awareness. The program was inspired by first-generation MBIs: MBSR (Kabat-Zinn, 1990) and MBCT (Segal et al., 2002) and second-generation MBIs: Self-Compassion (MSC; Neff \& Germer, 2013) and Cognitively based Compassion Training (CBCT; Ozawa-de Silva \& Dodson-Lavelle, 2011; Ozawa-de Silva \& Negi, 2013).

A specific online platform was created for the course. The intervention was delivered over 16 days (from 30th April to 15th May 2020) and consisted of 4 modules (total duration of the intervention: 428:28 min). Each module lasted for 4 days. After each set of 4 days, once a module had come to an end, the participants received personalized feedback about their home assignment, especially about keys to overcoming the 
difficulties and barriers that they may have encountered during the practice. Every module comprised the following three components: (1) minilectures (39:22 min) and home assignments consisting of (2) formal mindfulness and compassion practices (guided meditations) (309:67 min), and (3) selfreflection exercises (80 min approximately). A detailed outline of the program is included in Table 1. All the meditation practices of this intervention are available at this link (https:// drive.google.com/drive/folders/1 WZsCaW33 po 1JZ84cBlg5G8Jegw3pbnig?usp=sharing).

At the beginning of each module, participants were provided with the links to the videos (minilectures), audios (guided meditation practices), and home assignment questionnaires. These questionnaires included reflective questions regarding the topics covered in the minilectures (such as those included as examples in Table 1), and questions inquiring about their experience with each practice, frequency of practice, difficulties, and barriers to the practice. This information was used to assess the main obstacles students faced in relation to the practice, in order to provide them with the tools to cope with them through the feedback given to their home assignments. Participants were asked to answer the following questions after doing each meditation practice: "What audio have you practiced?, At what time of day do you practice?, At which part of the day do you do the practice?, What is the state of your mind, body and emotions before practice?, And how about after the practice?, Have any difficulties arisen?, If that is the case, please describe them. And finally, Have you found this practice useful?"

In order to overcome the possible challenges of a digital MBI we applied some of the best recommended practices in digital learning suggested by Mrazek et al. (2019). We focused on first-year psychology students because it is a population that the researchers have good knowledge of, so we had accurate information about the challenges they were facing in order to select the training outcomes that would be most relevant to them. In order to promote engagement and effective learning, we structured the intervention in short segments of information (4 modules with a 4-day duration for each), and we designed the contents and explanations in such a way that it would be interesting and engaging for the target group. The minilectures included a video of the mindfulness teacher from the waist up on one side of the screen explaining the main topics, and slides with interesting content on the other side. Finally, we addressed troubleshooting the audience's diversity by providing them with personalized feedback to the homework corresponding to each of the modules. In addition, we included a minilecture and reflective exercises about main difficulties that may arise with the practice of mindfulness and keys to overcome them.

The program was designed and delivered by an expert mindfulness teacher-practitioner and health psychologist with more than 10 years of experience teaching mindfulness to general and clinical populations. Moreover, the intervention was supervised by two psychologists with more than 10 years of experience in delivering MBI's to adolescents and adults.

\section{Measures}

As this study was conducted amidst the COVID-19 lockdown, all elements of the study were carried out via an electronic survey platform.

\section{Feasibility}

To assess feasibility, the study focused on five areas based on the feasibility criteria reviewed by Bowen et al. (2009) that best matched the needs and possibilities of the emergency situation in which this study was designed: Acceptability was evaluated as actual use of the program, i.e., time of practice, and the extent to which the participants found that mindfulness practice would be helpful in the future. It was measured with one item. Satisfaction was operationalized as the participants' opinion about the overall program, the extent to which they found the intervention useful and main difficulties with meditation practice. It was measured with 7 items. Ease of Implementation and Practicality, or the possibility of delivering it given these extraordinary circumstances, were evaluated as success of execution in this unprecedented setting, where all participants were confined in their homes. It was operationalized by the rate of retention, calculated by the percentage of post-intervention survey responses received on the online platform and the rate of adherence, calculated by the percentage of the participants that completed all home assignments. Limited Efficacy Testing was conducted on differences in stress, anxiety, and self-compassion levels from pre- to post-intervention assessment.

\section{Stress}

Perceived stress was evaluated using the Perceived Stress Scale (PSS-10), a widely used 10-item self-report instrument, which measures the degree to which life is considered stressful, unpredictable, uncontrollable, or overwhelming (Cohen \& Williamson, 1988). This version contains 10 items with responses given on a 5 -point Likert scale $(0-4)$. The scale has been translated and validated on the Spanish population. The Spanish version of the PSS-10 has adequate reliability (internal consistency, Cronbach's alpha $=0.82$, and test-retest, $r=$ 0.77), concurrent validity, and sensitivity (Remor, 2006).

\section{Anxiety}

Anxiety was evaluated using the State-Trait Anxiety Inventory (STAI) (Spielberger et al., 1970). This commonly 
Table 1 Outline of the E-Mindfulness intervention: summary of modules, components, and topics covered

Modules and educational objectives Component and topics covered

MODULE 1. PROMOTE MENTAL HEALTH AND AWARENESS

Minilecture: "What is Mindfulness?" (6:53 min) Introducing mindfulness, exploring ways in which mindfulness practice would be helpful for caring for ourselves and others during COVID-19 lockdown, psychoeducation on mental health and mental balance, attention, and automatic pilot

Minilecture: "How to practice Mindfulness?" $(6: 53 \mathrm{~min})$

How to practice mindfulness (basic attitudes), mindfulness mechanisms (attention, meta-awareness and self-regulation), mindful mind vs wandering mind, responding vs reacting

Homework:

-Breathing Pause meditation (7:26 min), at least 6 times during the next 4 days

-Reflective questions (20 min. approx.)

In this practice, participants were guided to cultivate mental balance by directing attention to breathing sensations and sustaining awareness onto them, cultivating mindfulness attitudes

E.g., What did you understand about mindfulness in the first minilecture? How do you think it can help you at this point in your life?

\section{MODULE 2. STRENGTHEN MENTAL HEALTH AND AWARENESS}

Minilecture:

-"Main difficulties in Mindfulness and how

o deal with them" (6:34 min)

Homework:

-Body Scan meditation (21:46 min), at least 4 times during the next 4 days

-Reflective questions (20 $\mathrm{min}$. approx.)

Exploring the main difficulties and barriers to mindful practice, discussing ways to deal with them, and dissolving mindfulness myths and stereotypes. The right intention and the paths towards it. The importance of ethical awareness, mindfulness attitudes, body awareness, and embodiment

In this practice, participants were guided to cultivate mental balance by directing attention to physical sensations, and sustaining awareness onto them, cultivating mindfulness attitudes

E.g., Have you encountered some of these difficulties in your practice of mindfulness? Please, explain in detail which ones and how the tips offered in the video could help you to overcome them

\section{MODULE 3. PROMOTE EMOTIONAL REGULATION THROUGH SELF-COMPASSION}

Minilecture:

-"Mindfulness and Self-Compassion" (6:59 min)

Homework:

-Self-compassion meditation (11:15 $\mathrm{min})$, at least 3 times during the next 4 days

Homework:

-Emotion regulation meditation (6:54 $\mathrm{min})$, at least 3 times during the next 4 days

Homework:

-Reflective questions (20 min. approx.)
The neurophysiology of stress, stressors during the COVID-19 confinement, the importance of self-care, self-compassion vs self-criticism, emotional awareness, tools to healthy emotional self-regulation

In this practice, participants were guided to cultivate the three components of self-compassion (mindfulness, common humanity, and kindness) in difficult moments

In this practice, participants were guided to take awareness of bodily feelings associated with emotions during difficult moments, and investigate them with equanimity, disidentifying themselves from thoughts and feelings, and taking awareness of the transient nature of phenomena

E.g., Do you treat yourself with self-compassion in your daily life or in the opposite way (with self-criticism, emotional reactivity, and overidentifying yourself with the problem faced)?

\section{MODULE 4. PROMOTE RESILIENCY THROUGH ETHICAL RESPONSIBILITY AND COMPASSION}

Minilecture:

-What is Compassion and how it can help you? $(8: 59 \mathrm{~min})$

Homework:

-Embodied Compassion meditation (11:22 min), at least 3 times during the next 4 days

Homework:

-Compassion in action meditation (11:19 $\mathrm{min}$ ),

at least 3 times during the next 4 days

Homework:

-Reflective exercises (20 min. approx.)
Introducing compassion, neuroscience and mental health, emotional barriers to compassion, the nature of reality: interdependence and interconnectedness applied to COVID-19 challenges, exploring what is meaningful in life, taking responsibility for our actions, tools to promote global wellbeing during the pandemic

In this practice, participants were guided to take awareness of bodily feelings while cultivating actively compassion. Also, they are encouraged to consider interdependence and to develop gratitude to others

In this practice, participants were guided to cultivate awareness, compassion, and ethical responsibility while interacting with others

E.g., Considering what is explained in the minilecture, in which ways do you think compassion could contribute both to your well-being and overall well-being? used scale used in both general and clinical populations contains 40 items with response categories given on a 4-point Likert scale (1-4), summing up to higher levels of anxiety in cases of higher total scores. Only the trait scale of the STAI was utilized, under the rationale of seeking changes on dispositional anxiety. This 20-item anxiety questionnaire measures the person's tendency to respond to stress. The scale has been validated in Spain and shows adequate psychometric properties and has adequate reliability (internal consistency, Cronbach's alpha $=0.84-0.87$ ) (Spielberger et al., 2001). 


\section{Self-Compassion}

The short form of the Self-Compassion Scale (SCS) is a 12-item self-report instrument that assesses selfcompassion (Neff, 2003). Total possible scores range from 12 to 60 , with response categories given on a 5-point Likert scale (1-5). Higher scores indicate higher levels of self-compassion. Unlike the full-length self-compassion scale (Neff, 2003), which contains six subscales, the short form produces a single score of self-compassion. The short form was used to minimize participant burden and encourage participation. The scale has been validated in Spain and shows adequate psychometric properties and has adequate reliability (internal consistency, and test-retest coefficient of 0.89 (95\% CI: 0.87-0.93) (Garcia-Campayo et al., 2014).

\section{Data Analyses}

Data analyses were performed using Jamovi (The Jamovi Project, 2020), a free and open statistical platform which provides the latest developments in statistical methodology. Test scores (PSS-10, STAI-t, SCS) were treated as scale variables. The internal consistency of the scale and internal consistency of items were analyzed with Cronbach's alpha. Pre- and post-intervention analyses were carried out performing a paired samples $t$ test. Prior to the tests, the assumption of normality of paired differences was checked using Shapiro-Wilk. The effect size and confidence intervals for the effect size were estimated using Hedges's g, instead of Cohen's D to guarantee positive unbiased results and to control correlation between measurements. Acceptability was evaluated using a (1-10) Likert Scale and analyzed using descriptive statistics (mean, standard deviation), and tested against the middle point of the scale (5.5) using 1 sample $t$ test.

\section{Reliability Analysis}

Cronbach's alpha was used to analyze the internal consistency of the scale and items of the three tests applied. Results show very high internal consistency. The Scale Reliability Analysis for PSS-10 shows a Cronbach's $\alpha$ $=0.8851$ in the pre-intervention scores and a Cronbach's $\alpha=0.9061$ in the pos-tintervention scores. The Scale Reliability Analysis for STAI shows a Cronbach's $\alpha$ $=0.9010$ in the pre-intervention scores and a Cronbach's $\alpha=0.8996$ in the post-intervention scores. The Scale Reliability Analysis for SCS shows a Cronbach's $\alpha$ $=0.8156$ in the pre-intervention scores and a Cronbach's $\alpha=0.8254$ in the post-intervention scores.

\section{Results}

\section{Acceptability}

The time of practice was evaluated as the total viewing time of the formal meditations on the online platform. It was $15.103 \mathrm{~min}$ per participant. In response to the question: "Considering your experience with the program, in which ways do you feel that the practice of mindfulness would serve you in the future?" The most frequently expected benefits were the following: improved emotional regulation $(86 \%)$, self-awareness and self-connection (74\%), and better understanding of oneself and others $(65 \%)$.

\section{Satisfaction}

The mean ratings for overall satisfaction, as well as usefulness and areas of helpfulness, were high (Table 2). The results relative to satisfaction with the program show a mean score of 7.80 ( $\mathrm{SD}=1.23$ ). Most noticeably, when asking students about their capacity to become more aware of their emotions the mean score was $8.14(\mathrm{SD}=1.05)$. The ability to take care of themselves during difficult times accounted for an average of 7.48 ( $\mathrm{SD}=1.38$ ). Finally, the mean score for the students self-perceived capacity to regulate their emotions was 7.24 $(\mathrm{SD}=1.53)$, and for their self-perceived attention and concentration skills was $7.26(\mathrm{SD}=1.44)$. Items results were tested against the middle of the scale (5.50). In all five cases, highly significant results were noticed.

Also, when asked "Have you found the program useful?" $87.87 \%$ answered yes, $10.61 \%$ answered maybe, and $1.51 \%$ answered no. Finally, when asked about the main difficulties with the practice of meditation practice included in their home assignments, the most frequently referred difficulties were those related to mind-wandering and concentration ( $85.71 \%)$, insecurity about their performance in the practice of mindfulness $(72.37 \%)$, and self-criticism $(56.58 \%)$.

\section{Implementation and Practicality}

Seventy-six of the 87 students $(87.36 \%)$ that were invited to join the study agreed to participate and completed the preintervention test. The post-intervention test was completed by 70 students (retention rate of $92.11 \%$ ). However, 4 responses were dropped due to code mismatch. Therefore, the actual retention rate of the study was $86.84 \%$ (66 valid responses from 76 participants). $96.97 \%$ of the participants delivered their home assignment for modules 1 and 2, 92.42\% for module 3 , and $95.54 \%$ for module 4 . This resulted in an average adherence rate for the whole program of $94.95 \%$. These rates indicate a high degree of success of execution. 


\begin{tabular}{|c|c|c|c|c|c|c|c|c|}
\hline & \multirow[b]{3}{*}{ Mean (SD) } & \multicolumn{2}{|l|}{ Statistic } & \multirow[b]{3}{*}{$p$} & \multicolumn{4}{|l|}{ Effect size } \\
\hline & & \multirow[b]{2}{*}{ Test } & \multirow[b]{2}{*}{ Value } & & \multirow[b]{2}{*}{ Test } & \multirow[b]{2}{*}{ Value } & \multicolumn{2}{|c|}{$\begin{array}{l}95 \% \text { confidence } \\
\text { interval }\end{array}$} \\
\hline & & & & & & & Lower & Upper \\
\hline $\begin{array}{l}\text { To which extent has it helped you to take better care of } \\
\text { yourself in difficult times }\end{array}$ & $7.48(1.38)$ & Student's $t$ & 20.38 & $<.001$ & Hedges's g & 2.49 & 2.00 & 2.98 \\
\hline $\begin{array}{l}\text { To which extent has it helped you to become more aware } \\
\text { of your emotions? }\end{array}$ & $8.14(1.05)$ & Student's $t$ & 9.25 & $<.001$ & Hedges's g & 1.13 & 0.82 & 1.44 \\
\hline To which extent has it helped you to better regulate your emotions? & $7.24(1.53)$ & Student's $t$ & 9.92 & $<.001$ & Hedges's g & 1.21 & 0.89 & 1.53 \\
\hline $\begin{array}{l}\text { To which extent has it helped you to improve your attention and } \\
\text { concentration skills? }\end{array}$ & $7.26(1.44)$ & Student's $t$ & 11.65 & $<.001$ & Hedges's g & 1.43 & 1.08 & 1.77 \\
\hline Overall, how would you rate your satisfaction with the program? & $7.80(1.23)$ & Student's $t$ & 15.20 & $<.001$ & Hedges's g & 1.8602 & 1.46 & 2.26 \\
\hline
\end{tabular}

$\mathrm{H}_{1}>5.5$

\section{Limited Efficacy Testing}

Stress and anxiety levels decreased significantly after the intervention. Mean stress levels were reduced from 23.30 to 19.73 (mean difference $=3.57, p<0.001$, Hedges's g=0.51). Mean trait anxiety levels were reduced from 31.62 to 26.79 (mean difference $=4.83, p<0.001$, Hedges's $g=0.61$ ). In both cases, assumption of normality was checked and met (Shapiro-Wilk). Selfcompassion improved significantly after the intervention. Selfcompassion levels were augmented from 17.20 to 19.20 (mean difference $=-2.00, p<0.001$, Hedges's g=0.70). Normality assumption was checked and met (Shapiro-Wilk). In all three cases, highly significant results were detected. Moreover, Hedges's g results over the three tests suggested a medium effect size of the intervention over these participants. Table 3 shows pre- and post-intervention mean differences, $p$ value and effect size. Figure 1 shows pre- and post-intervention comparisons: means, medians, and confidence intervals for means.

\section{Discussion}

The purpose of the current study was to examine the feasibility of providing a brief online mindfulness and compassion intervention to first-year psychology students at a time in which they were deeply emotionally impacted by the COVID-19 lockdown. Overall, the results demonstrated that the MBI was feasible and that the participants found the intervention useful. Moreover, significant effects were found for mental health improvements, with medium effect sizes in all the variables evaluated. Participants showed significant improvements in pre-post scores of perceived stress (PSS-10), trait anxiety (STAI-t), and self-compassion (SCS-short form).
These promising findings warrant further investigation within a randomized controlled trial.

The finding of reduced perceived stress and anxiety is consistent with the outcomes of MBIs in the university student population. This includes a recent meta-analytic study investigating MBIs for university students (Dawson et al., 2020), and a meta-analytic study investigating brief mindfulness training for negative affectivity (Schumer et al., 2018). However, all of these studies evaluated randomized controlled trials. When compared to similar studies of mindfulness interventions delivered to university students, the results of this study regarding feasibility and adherence are slightly higher than those usually found (e.g., Centeno, 2020; Danilewitz et al., 2018; Finlay-Jones et al., 2017; Forbes et al., 2018). However, due to the exceptional setting of lockdown, the results of the present study cannot be compared to other studies conducted prior to the pandemic.

Results from our study regarding the high levels of anxiety and stress in university students during the COVID-19 lockdown are in line with other studies carried out at the same time in the university population in Spain (Odriozola-González et al., 2020), as well as in other countries worldwide (Cao et al., 2020; Kaparounaki et al., 2020; Wang et al., 2020). As these and other studies have pointed out, the young adult population is a risk group for COVID-19 at a psychological level (Huang \& Zhao, 2020; Ozamiz-Etxebarria et al., 2020). The deep psychological impact that the lockdown has had on university students could be caused by stress triggered by excessive social media consumption (Hong et al., 2020; Zhao \& Zhou, 2020). Indeed, during the COVID-19 crisis there has been a spread of misinformation, fake news, and alarming images in social media, which could amplify fear, anxiety, stress, and worry (Ozamiz-Etxebarria et al., 2020; Zhao \& Zhou, 2020). It is important to note that psychological stress is widely viewed as an individual's interpretation that 
Table 3 Pre- and post-intervention comparisons: mean differences, $p$ value and effect size

\begin{tabular}{|c|c|c|c|c|c|c|c|c|c|c|}
\hline & \multirow[b]{3}{*}{ Mean difference } & & & \multicolumn{2}{|l|}{ Statistic } & \multirow[b]{3}{*}{$p$} & \multicolumn{4}{|l|}{ Effect size } \\
\hline & & \multicolumn{2}{|c|}{$95 \%$ confidence interval } & \multirow[b]{2}{*}{ Test } & \multirow[b]{2}{*}{ Value } & & \multirow[b]{2}{*}{ Test } & \multirow[b]{2}{*}{ Value } & \multicolumn{2}{|c|}{$95 \%$ confidence interval } \\
\hline & & Lower & Upper & & & & & & Lower & Upper \\
\hline SCS & -2.00 & 1.25 & 2.75 & Student's $t$ & -5.69 & $<.001$ & Hedges's g & 0.70 & 0.43 & 0.96 \\
\hline STAIR & 4.83 & 2.89 & 6.78 & Student's $t$ & 4.96 & $<.001$ & Hedges's g & 0.61 & 0.34 & 0.87 \\
\hline PSS10 & 3.58 & 1.88 & 5.27 & Student's $t$ & 4.20 & $<.001$ & Hedges's g & 0.51 & 0.26 & 0.77 \\
\hline
\end{tabular}

the demands of the environment exceed their personal resources to deal with them, endangering their well-being (Lazarus \& Folkman, 1984). The most significant implication of this definition is that by providing individuals with resources to effectively cope with stressors, the onset of psychological stress could be prevented. Hence, it is of utmost importance for policymakers, public health agencies, and educational institutions to monitor young adults' mental health and to provide them with resources to effectively regulate their emotions and cope with challenges.

As COVID-19 continues to spread in the world, it has become a global mental health challenge. In this context, online MBIs may constitute invaluable tools of primary and secondary prevention for mental health during one of the most difficult times of the pandemic (Ho et al., 2020). All in all, digital MBIs represent a promising path for promoting mental health in a world in crisis. While this modality of MBI faces numerous challenges, they can be overcome as long as it is applied through some of the best practices in digital learning (Mrazek et al., 2019), like those considered in the current study.

\section{Limitations and Future Research}

There were several limitations of this study such as the small sample size, the lack of a randomized control group and the absence of follow-up. These factors seriously limit the generalizability of the results of the present study, designed to test the feasibility of this intervention at the onset of the COVID-
19 pandemic. The empirically informed power analysis conducted will guide future randomized controlled trials that will solve the present limitations.

Regarding measurement of feasibility outcomes, they were assessed via self-report, which can lead to common method bias. So that variations in the participant's responses may be caused by the measurement instrument rather than the actual variations in the constructs being measured (Podsakoff et al., 2003). Moreover, participants were not asked about specific components of the E-Mindfulness intervention which could have helped determine which aspects of the intervention were and were not helpful to students (e.g., theoretical lectures, formal mindfulness and compassion practices and self-reflection exercises).

The present study had an adherence rate of $93 \%$ and a medium effect size on mental health. Commonly, online MBIs have suffered lower intervention adherence rates, with rates varying between $39.5 \%$ and $92 \%$, and small effect sizes on mental health (e.g., Centeno, 2020; Danilewitz et al., 2018; Finlay-Jones et al., 2017; Forbes et al., 2018; Spijkerman et al., 2016). The high retention and participation rates of this study could be due to some intervention features, lockdown effects, and sample characteristics. At the time of the initiation of this study, participants had been confined in their homes for almost 2 months. As other studies have shown, as the time spent in lockdown progressed, psychological symptoms got worse (Ozamiz-Etxebarria et al., 2020). It may be in the interest of future lines of research to evaluate the therapeutic alliance and motivation of the participants to gain further insight into what can make online interventions easier to adhere to.
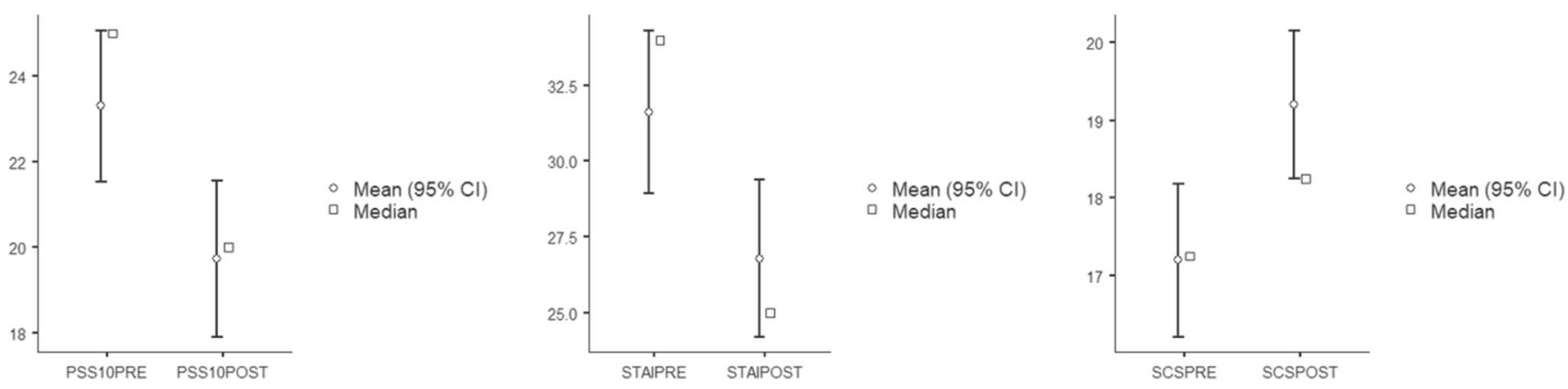

Figure 1 Pre- and post-intervention comparisons:means, medians, and confidence intervals for means. 
The familiarity between students and the mindfulness instructor may account for the results on acceptability, participation, and retention rates. Indeed, a recent review shows that self-guided interventions may not be as effective as those in which there is an active relationship between the participants and the instructor (Fischer et al., 2020). Some of the variance in engagement and outcomes of E-mental health interventions may be accounted for by the common and relational factors embedded within the technologies themselves (Cavanagh \& Millings, 2013). In this respect, the intervention in the current study was delivered by a professor already known to the participants from a previously completed face-to-face course on the psychology of motivation. Besides, the minilectures consisted of a video of the mindfulness teacher, from the waist up, explaining the main topics. Furthermore, all the meditations were recorded with the voice of this same teacher. Hence, future studies could evaluate the unique contribution of these relational factors to the intervention outcomes.

Even considering the modest nature of this study and its limitations, we hope that it may serve to inspire others to continue exploring the potential value of mindfulness and compassion to promote mental health and well-being during global challenges such as the COVID-19 pandemic.

Author Contributions MGG: designed and executed the study and wrote the paper. JCA: collaborated with the development of the electronic surveys and managed data analyses. EZP, SFC, and JGL: collaborated with the design, writing, and editing of the final manuscript. All authors approved the final version of the manuscript prior to submission.

\section{Declarations}

Ethical Approval The study was approved by the Ethics Board of the European University of the Atlantic. All procedures were in accordance with the ethical standards laid down in the 1964 Helsinki Declaration and its later amendments.

Informed Consent Written informed consent was obtained from all participants included in the study. All participants were provided with a statement that their responses were anonymous.

Conflict of Interest The authors declare that they have no conflict of interest.

\section{References}

Araújo, F., de Lima, L., Cidade, P., Nobre, C. B., \& Neto, M. (2020). Impact of Sars-Cov-2 and its reverberation in global higher education and mental health. Psychiatry Research, 288, 112977. https:// doi.org/10.1016/j.psychres.2020.112977.

Arch, J. J., Brown, K. W., Dean, D. J., Landy, L. N., Brown, K. D., \& Laudenslager, M. L. (2014). Self-compassion training modulates alpha-amylase, heart rate variability, and subjective responses to social evaluative threat in women. Psychoneuroendocrinology, 42, 49-58. https://doi.org/10.1016/j.psyneuen.2013.12.018.

Auerbach, R. P., Alonso, J., Axinn, W. G., Cuijpers, P., Ebert, D. D., Green, J. G., Hwang, I., Kessler, R. C., Liu, H., Mortier, P., Nock, M. K., Pinder-Amaker, S., Sampson, N. A., Aguilar-Gaxiola, S., AlHamzawi, A., Andrade, L. H., Benjet, C., Caldas-de-Almeida, J. M., Demyttenaere, K., Florescu, S., et al. (2016). Mental disorders among college students in the World Health Organization World Mental Health Surveys. Psychological Medicine, 46(14), 29552970. https://doi.org/10.1017/S0033291716001665.

Bowen, D. J., Kreuter, M., Spring, B., Cofta-Woerpel, L., Linnan, L., Weiner, D., Bakken, S., Kaplan, C. P., Squiers, L., Fabrizio, C., \& Fernandez, M. (2009). How we design feasibility studies. American Journal of Preventive Medicine, 36(5), 452-457. https://doi.org/10. 1016/j.amepre.2009.02.002.

Brooks, S. K., Webster, R. K., Smith, L. E., Woodland, L., Wessely, S., Greenberg, N., \& Rubin, G. J. (2020). The psychological impact of quarantine and how to reduce it: Rapid review of the evidence. Lancet, 395(10227), 912-920. https://doi.org/10.1016/S01406736(20)30460-8.

Bruffaerts, R., Mortier, P., Kiekens, G., Auerbach, R. P., Cuijpers, P., Demyttenaere, K., Green, J. G., Nock, M. K., \& Kessler, R. C. (2018). Mental health problems in college freshmen: Prevalence and academic functioning. Journal of Affective Disorders, 225, 97-103. https://doi.org/10.1016/j.jad.2017.07.044.

Breines, J. G., Thoma, M. V., Gianferante, D., Hanlin, L., Chen, X., \& Rohleder, N. (2014). Self-compassion as a predictor of interleukin-6 response to acute psychosocial stress. Brain, Behavior, and Immunity, 37, 109-114. https://doi.org/10.1016/j.bbi.2013.11.006.

Cao, W., Fang, Z., Hou, G., Han, M., Xu, X., Dong, J., \& Zheng, J. (2020). The psychological impact of the COVID-19 epidemic on college students in China. Psychiatry Research, 287, 112934. https://doi.org/10.1016/j.psychres.2020.112934.

Cavanagh, K., \& Millings, A. (2013). Interpersonal computing: The role of therapeutic relationships in e-mental health. Journal of Contemporary Psychotherapy, 43(4), 197-120. https://doi.org/10. 1007/s10879-013-9242-z.

Centeno, R. (2020). Effect of mindfulness on empathy and self-compassion: An adapted MBCT program on Filipino college students. Behavioral Sciences, 10(3), 61. https://doi.org/10.3390/bs1003006.

Chiesa, A., \& Serretti, A. (2011). Mindfulness based cognitive therapy for psychiatric disorders: A systematic review and meta-analysis. Psychiatry Research, 187(3), 441-453. https://doi.org/10.1016/j. psychres.2010.08.011.

Chiodelli, R., Mello, L., Jesus, S. N., Beneton, E. R., Russel, T., \& Andretta, I. (2020). Mindfulness-based interventions in undergraduate students: A systematic review. Journal of American College Health, 1-10. Advance online publication. https://doi.org/10.1080/ 07448481.2020 .1767109$.

Cohen, S., \& Williamson, G. (1988). Perceived stress in a probability sample of the United States. In S. Spacapam \& S. Oskamp (Eds.), The social psychology of health: Claremont Symposium on applied social psychology (pp. 31-67). Newbury Park, CA: Sage.

Cohen, S., Janicki-Deverts, D., \& Miller, G. E. (2007). Psychological stress and disease. JAMA, 298(14), 1685-1687. https://doi.org/10. 1001/jama.298.14.1685.

Cooke, R., Bewick, B. M., Barkham, M., Bradley, M., \& Audin, K. (2006). Measuring, monitoring and managing the psychological well-being of first year university students. British Journal of Guidance and Counselling, 34(4), 505-517. https://doi.org/10. 1080/03069880600942624.

Danilewitz, M., Koszycki, D., Maclean, H., Sanchez-Campos, M., Gonsalves, C., Archibald, D., \& Bradwejn, J. (2018). Feasibility and effectiveness of an online mindfulness meditation program for medical students. Canadian Medical Education Journal, 9(4), e15e25. 
Dawson, A. F., Brown, W. W., Anderson, J., Datta, B., Donald, J. N., Hong, K., Allan, S., Mole, T. B., Jones, P. B., \& Galante, J. (2020). Mindfulness-based interventions for university students: A systematic review and meta-analysis of randomized controlled trials. Applied Psychology. Health and Well-Being, 12(2), 384-410. https://doi.org/10.1111/aphw.12188.

El Morr, C., Ritvo, P., Ahmad, F., Moineddin, R., \& Team, M. V. C. (2020). Effectiveness of an 8-week web-based mindfulness virtual community intervention for university students on symptoms of stress, anxiety, and depression: Randomized controlled trial. JMIR Mental Health, 7(7), e18595. https://doi.org/10.2196/18595.

Finlay-Jones, A., Kane, R., \& Rees, C. (2017). Self-Compassion Online: A pilot study of an internet-based self-compassion cultivation program for psychology trainees. Journal of Clinical Psychology, 73(7), 797-816. https://doi.org/10.1002/jclp.22375.

Fischer, R., Bortolini, T., Karl, J. A., Zilberberg, M., Robinson, K., Rabelo, A., Gemal, L., Wegerhoff, D., Nguyễn, T., Irving, B., Chrystal, M., \& Mattos, P. (2020). Rapid review and meta-metaanalysis of self-guided interventions to address anxiety, depression, and stress during COVID-19 social distancing. Frontiers in Psychology, 11, 563876. https://doi.org/10.3389/fpsyg.2020. 563876.

Forbes, L., Gutierrez, D., \& Johnson, S. K. (2018). Investigating adherence to an online introductory mindfulness program. Mindfulness, 9(1), 271-282. https://doi.org/10.1007/s12671-017-0772-4.

Garcia-Campayo, J., Navarro-Gil, M., Andrés, E., Montero-Marin, J., López-Artal, L., \& Demarzo, M. P. (2014). Validation of the Spanish versions of the long ( 26 items) and short (12 items) forms of the self-compassion scale (SCS). Health and Quality of Life Outcomes, 12(4). https://doi.org/10.1186/1477-7525-12-4.

Goldberg, S. B., Riordan, K. M., Sun, S., \& Davidson, R. J. (2021). The empirical status of mindfulness-based interventions: A systematic review of 44 meta-analyses of randomized controlled trials. Perspectives on Psychological Science: a Journal of the Association for Psychological Science. 1745691620968771. Advance online publication. https://doi.org/10.1177/ 1745691620968771.

González-García, M., Borràs, X., López, J. G., \& McNeil, K. G. (2016). Mindfulness-based cognitive therapy application for people living with chronic disease: the case of HIV. In S. Eisendrath (Ed.), Mindfulness-Based Cognitive Therapy: Innovative applications (pp. 95-100). Springer. https://doi.org/10.1007/978-3-319-298665 8.

González-Sanguino, C., Ausín, B., Castellanos, M. Á., Saiz, J., LópezGómez, A., Ugidos, C., \& Muñoz, M. (2020). Mental health consequences during the initial stage of the 2020 Coronavirus pandemic (COVID-19) in Spain. Brain, Behavior, and Immunity, 87, 172176. https://doi.org/10.1016/j.bbi.2020.05.040.

Halladay, J. E., Dawdy, J. L., McNamara, I. F., Chen, A. J., Vitoroulis, I., McInnes, N., \& Munn, C. (2019). Mindfulness for the mental health and well-being of post-secondary students: A systematic review and meta-analysis. Mindfulness, 10(3), 397-414. https://doi.org/10. 1007/s12671-018-0979-Z.

Ho, C. S., Chee, C. Y., \& Ho, R. C. (2020). Mental health strategies to combat the psychological impact of COVID-19 beyond paranoia and panic. Annual Academic Medicine Singapore, 49(1), 1-3.

Hong, W., Liu, R. D., Ding, Y., Fu, X., Zhen, R., \& Sheng, X. (2020). Social media exposure and college students' mental health during the outbreak of COVID-19: The mediating role of rumination and the moderating role of mindfulness. Cyberpsychology, Behavior and Social Networking. https://doi.org/10.1089/cyber.2020.0387. Advance online publication, https://doi.org/10.1089/cyber.2020. 0387.

Horowitz, M. J., Wilner, N., Kaltreider, N., \& Alvarez, W. (1980). Signs and symptoms of posttraumatic stress disorder. Archives of General
Psychiatry, 37(1), 85-92. https://doi.org/10.1001/archpsyc.1980. 01780140087010

Huang, Y., \& Zhao, N. (2020). Generalized anxiety disorder, depressive symptoms and sleep quality during COVID-19 outbreak in China: a web-based cross-sectional survey. Psychiatry Research, 11, 1-19. https://doi.org/10.1016/j.psychres.2020.112954.

Inwood, E., \& Ferrari, M. (2018). Mechanisms of change in the relationship between self-compassion, emotion regulation, and mental health: A systematic review. Applied psychology. Health and Well-being, 10(2), 215-235. https://doi.org/10.1111/aphw.12127.

Jiménez, Ó., Sánchez-Sánchez, L. C., \& García-Montes, J. M. (2020). Psychological impact of COVID-19 confinement and its relationship with meditation. International Journal of Environmental Research and Public Health, 17(18), 6642. https://doi.org/10. 3390/ijerph17186642.

Kabat-Zinn, J. (1990). Full catastrophe living: Using the wisdom of your body and mind to face stress, pain and illness. Delacorte.

Kaparounaki, C. K., Patsali, M. E., Mousa, D. V., Papadopoulou, E., Papadopoulou, K., \& Fountoulakis, K. N. (2020). University students' mental health amidst the COVID-19 quarantine in Greece. Psychiatry Research, 290, 113111. Advance online publication. https://doi.org/10.1016/j.psychres.2020.113111.

Kirby, J. N., Tellegen, C. L., \& Steindl, S. R. (2017). A meta-analysis of compassion-based interventions: Current state of knowledge and future directions. Behavior Therapy, 48(6), 778-792. https://doi. org/10.1016/j.beth.2017.06.003.

Khoury, B., Sharma, M., Rush, S., \& Fournier, C. (2015). Mindfulnessbased stress reduction for healthy individuals: A meta-analysis. Journal of Psychosomatic Research, 78(6), 519-528. https://doi. org/10.1016/j.jpsychores.2015.03.009.

Khoury, B. (2020). The Root Causes of COVID-19 screech for compassion. Mindfulness, 11, 1910-1913.

Lazarus, R. S., \& Folkman, S. (1984). Stress, appraisal, and coping. Springer.

Liu, C. H., Stevens, C., Wong, S., Yasui, M., \& Chen, J. A. (2019). The prevalence and predictors of mental health diagnoses and suicide among U.S. college students: Implications for addressing disparities in service use. Depression and Anxiety, 36(1), 8-17. https://doi.org/ 10.1002/da.22830.

Luo, Y., Meng, R., Li, J., Liu, B., Cao, X., \& Ge, W. (2019). Selfcompassion may reduce anxiety and depression in nursing students: A pathway through perceived stress. Public Health, 174, 1-10. https://doi.org/10.1016/j.puhe.2019.05.015.

Luykx, J. J., Vinkers, C. H., \& Tijdink, J. K. (2020). Psychiatry in times of the coronavirus disease 2019 (covid-19) pandemic: An imperative for psychiatrists to act now. JAMA Psychiatry, 77(11), 10971098. https://doi.org/10.1001/jamapsychiatry.2020.1225.

Matiz, A., Fabbro, F., Paschetto, A., Cantone, D., Paolone, A. R., \& Crescentini, C. (2020). Positive impact of mindfulness meditation on mental health of female teachers during the COVID-19 outbreak in Italy. International Journal of Environmental Research and Public Health, 17(18), 6450. https://doi.org/10.3390/ ijerph17186450.

McConville, J., McAleer, R., \& Hahne, A. (2017). Mindfulness training for health profession students-the effect of mindfulness training on psychological well-being, learning and clinical performance of health professional students: A systematic review of randomized and non-randomized controlled trials. Explore, 13(1), 26-45. https://doi.org/10.1016/j.explore.2016.10.002.

Mrazek, A. J., Mrazek, M. D., Cherolini, C. M., Cloughesy, J. N., Cynman, D. J., Gougis, L. J., Landry, A. P., Reese, J. V., \& Schooler, J. W. (2019). The future of mindfulness training is digital, and the future is now. Current Opinion in Psychology, 28, 81-86. https://doi.org/10.1016/j.copsyc.2018.11.012. 
Neff, K. D. (2003). Development and validation of a scale to measure self-compassion. Self and Identity, 2(3), 223-250. https://doi.org/10. 1080/15298860309027.

Neff, K. D., \& Germer, C. K. (2013). A pilot study and randomized controlled trial of the mindful self-compassion program. Journal of Clinical Psychology, 69(1), 28-44. https://doi.org/10.1002/jclp. 21923.

Odriozola-González, P., Planchuelo-Gómez, Á., Irurtia, M. J., \& de LuisGarcía, R. (2020). Psychological effects of the COVID-19 outbreak and lockdown among students and workers of a Spanish university. Psychiatry Research, 290, 113108. https://doi.org/10.1016/j. psychres.2020.113108.

Otu, A., Charles, C. H., \& Yaya, S. (2020). Mental health and psychosocial well-being during the COVID-19 pandemic: The invisible elephant in the room. International Journal of Mental Health Systems, 14(1), 1-5. https://doi.org/10.1186/s13033-020-00371-w.

Ozamiz-Etxebarria, N., Idoiaga-Mondragón, N., Dosil-Santamaría, M., \& Picaza-Gorrotxategi, M. (2020). Psychological symptoms during the two stages of lockdown in response to the covid-19 outbreak: An investigation in a sample of citizens in northern Spain. Frontiers in Psychology, 11(1491). https://doi.org/10.3389/fpsyg.2020. 01491.

Ozawa-de Silva, B., \& Dodson-Lavelle, B. (2011). An education of heart and mind: Practical and theoretical issues in teaching cognitivebased compassion training to children. Practical Matters, 1(4), 128.

Ozawa-de Silva, B., \& Negi, L. T. (2013). Cognitively-based compassion training: Protocol and key concepts. In M. Bolz \& T. Singer (Eds.), Compassion: Bridging theory and practice (pp. 416-437). Max Planck Institute for Human Cognitive and Brain Sciences.

Platto, S., Zhou, J., Wang, Y., Wang, H., \& Carafoli, E. (2021). Biodiversity loss and COVID-19 pandemic: The role of bats in the origin and the spreading of the disease. Biochemical and Biophysical Research Communications, 538, 2-13. https://doi.org/ 10.1016/j.bbrc.2020.10.028.

Pedersen, A., Zachariae, R., \& Bovbjerg, D. H. (2010). Influence of psychological stress on upper respiratory infection-A metaanalysis of prospective studies. Psychosomatic Medicine, 72(8), 823-832. https://doi.org/10.1097/PSY.0b013e3181f1d003.

Podsakoff, P. M., MacKenzie, S. B., Lee, J. Y., \& Podsakoff, N. P. (2003). Common method biases in behavioral research: A critical review of the literature and recommended remedies. The Journal of Applied Psychology, 88(5), 879-903. https://doi.org/10.1037/00219010.88.5.879.

Ramler, T. R., Tennison, L. R., Lynch, J., et al. (2016). Mindfulness and the college transition: The efficacy of an adapted mindfulness-based stress reduction intervention in fostering adjustment among firstyear students. Mindfulness, 7, 179-188. https://doi.org/10.1007/ s12671-015-0398-3.

Remor, E. (2006). Psychometric properties of a European Spanish version of the perceived stress scale (PSS). The Spanish Journal of Psychology, 9(1), 86-93. https://doi.org/10.1017/ s1138741600006004.

Ross, S. E., Niebling, B. C., \& Heckert, T. M. (1999). Sources of stress among college students. Social Psychology, 61(5), 841-846.

Schumer, M. C., Lindsay, E. K., \& Creswell, J. D. (2018). Brief mindfulness training for negative affectivity: A systematic review and meta-analysis. Journal of Consulting and Clinical Psychology, 86(7), 569-583. https://doi.org/10.1037/ccp0000324.

Segal, Z. V., Williams, J. M., \& Teasdale, J. D. (2002). Mindfulnessbased cognitive therapy for depression: A new approach to preventing relapse. The Guilford Press.

Shigemura, J., Ursano, R. J., Morganstein, J. C., Kurosawa, M., \& Benedek, D. M. (2020). Public responses to the novel 2019 coronavirus (2019-nCoV) in Japan: Mental health consequences and target populations. Psychiatry and Clinical Neurosciences, 74(4), 281-282. https://doi.org/10.1111/pcn.12988.

Shonin, E., Van Gordon, W., Compare, A., et al. (2015). Buddhistderived loving-kindness and compassion meditation for the treatment of psychopathology: A systematic review. Mindfulness, 6 , 1161-1180. https://doi.org/10.1007/s12671-014-0368-1.

Shonin, E., Van Gordon, W., Garcia-Campayo, J., \& Griffiths, M. D. (2017). Can compassion help cure health-related disorders? The British journal of general practice: the journal of the Royal College of General Practitioners, 67(657), 177-178. https://doi. org/10.3399/bjgp17X690329.

Spielberger, C., Gorsuch, R., \& Lushene, R. (1970). Manual for the statetrait anxiety inventory. Consulting Psychologist Press.

Spielberger, C, Gorsuch, R. \& Lushene, R. (2001). STAI, Cuestionario de Ansiedad Estado/Rasgo. TEA.

Spijkerman, M. P., Pots, W. T., \& Bohlmeijer, E. T. (2016). Effectiveness of online mindfulness-based interventions in improving mental health: A review and meta-analysis of randomized controlled trials. Clinical Psychology Review, 45, 102-114. https://doi.org/10.1016/j. cpr.2016.03.009.

Storrie, K., Ahern, K., \& Tuckett, A. (2010). A systematic review: Students with mental health problems-A growing problem. International Journal of Nursing Practice, 16(1), 1-6. https://doi. org/10.1111/j.1440-172X.2009.01813.X.

Tang, Y. Y., Hölzel, B. K., \& Posner, M. I. (2015). The neuroscience of mindfulness meditation. Nature reviews. Neuroscience, 16(4), 213 225. https://doi.org/10.1038/nrn3916.

The Jamovi Project (2020). Jamovi (Version 1.2) [Computer Software]. https://www.jamovi.org. Accessed 19 Apr 2021.

Tosevski, D. L., Milovancevic, M. P., \& Gajic, S. D. (2010). Personality and psychopathology of university students. Current Opinion in Psychiatry, 23(1), 48-52. https://doi.org/10.1097/YCO. $0 \mathrm{~b} 013 \mathrm{e} 328333 \mathrm{~d} 625$.

Vago, D. R., \& Silbersweig, D. A. (2012). Self-awareness, self-regulation, and self-transcendence (S-ART): A framework for understanding the neurobiological mechanisms of mindfulness. Frontiers in Human Neuroscience, 6, 296. https://doi.org/10.3389/fnhum.2012. 00296.

Van Gordon, W., Shonin, E., \& Griffiths, M. D. (2015). Towards a second-generation of mindfulness-based interventions. The Australian and New Zealand Journal of Psychiatry, 49(7), 591592. https://doi.org/10.1177/0004867415577437.

Wang, C., Pan, R., Wan, X., Tan, Y., Xu, L., Ho, C. S., \& Ho, R. C. (2020). Immediate psychological responses and associated factors during the initial stage of the 2019 coronavirus disease (COVID-19) epidemic among the general population in China. International Journal of Environmental Research and Public Health, 17(5), 1729. https://doi.org/10.3390/ijerph17051729.

Wallace, B. A. (2005). Genuine happiness: Meditation as the path to fulfillment. Wiley.

World Health Organization (2020). Coronavirus disease (covid-2019) situation reports. https:/www.who.int/docs/default-source/ coronaviruse/situation-reports/20200311-sitrep-51-covid-19.pdf? sfvrsn=1ba62e57 10. Accessed 19 Mar 2021.

Zhao, N., \& Zhou, G. (2020). Social media use and mental health during the COVID-19 pandemic: Moderator role of disaster stressor and mediator role of negative affect. Applied Psychology. Health and Well-Being, 12(4), 1019-1038. https://doi.org/10.1111/aphw. 12226

Publisher's Note Springer Nature remains neutral with regard to jurisdictional claims in published maps and institutional affiliations. 